\title{
BIOECONOMY - OPPORTUNITIES AND THREATS IN MALOPOLSKA VOIVODSHIP (POLAND)
}

Katarzyna KOKOSZKA, Institute of Economy and Social Sciences, Department of Economy and Economic Policy, Faculty of Agriculture and Economics, University of Agriculture in Krakow, Al. Mickiewicza 21, 31-120 Krakow, Poland; k.kokoszka@ur.krakow.pl (corresponding author)

Malgorzata PINK, Institute of Economy and Social Sciences, Department of Economy and Economic Policy, Faculty of Agriculture and Economics, University of Agriculture in Krakow, Al. Mickiewicza 21, 31-120 Krakow, Poland; m.pink@ur.krakow.pl

The main objective of the article is to indicate the main challenges and development opportunities related to the bioeconomy, shown in the regional layout on the example of the Małopolska voivodeship.

The theoretical part of a paper is basing on a review of the literature regarding a concept of bioeconomy. It finds is conclusions in a model of 'bio-economy triad of challenges', that the conventional economy is facing. The issues of bioeconomy in this paper are presented in a context of:

- processes taking place between enterprises, consumers and the state,

- challenges for qualitative and quantitative economic development.

Referring to the above-mentioned model, it was stated that the bioeconomy should be the main direction of development as part of the smart specialization strategy for Małopolska. This will allow, among others development of functional value chains, increasing the added value of production and the possibility of sustainable management of natural resources.

Attention was also paid to conditions of development that may constitute significant barriers in shaping the bio-profile of the economy on a regional basis:

- environmental, in the sense of sustainable access to natural resources;

- social, understood as the quality of social capital and access to a qualified workforce;

- institutional, being the state's responsibility and related to the law, providing adequate infrastructure or adequate expenditures for R\&D. It was noticed that Małopolska is characterized by a dual development model - on the one hand, we are dealing with sectors of modern technologies concentrated in the provincial city and some poviat cities. On the other hand, when we talk about the raw material sphere, one can talk about development destimulants, i.e. agrarian structure, the problem of fallowing land or the lack of a qualified workforce in rural areas.

Keywords: bioeconomy, Malopolska voivodship, opportunities and threats of bioeconomy, sustainable development

\section{INTRODUCTION}

The concept of the bioeconomy is closely linked to the idea of a steady development in terms of balancing different types of order - social, economic and environmental order- thanks to formal institutions and values. Furthermore, the idea of the bioeconomy is also connected with the sustainability of developmental capitals and the capitals of physical, human, economic and social kind through the creation and dissemination of industrial, organizational, product, institutional and social innovation. It could be argued that the bioeconomy may be yet another cognitive tool or another way of operationalizing objectives of a balanced development.

So understood bioeconomy can be a form of transformation of business in accordance with the principles of the balanced development, the activity based on the application of the biotechnology, bio-processes and bio-based products in order to create goods and services, and finally, the smart specialisation in the countries of the European Union in sectors such as agriculture, fisheries, forestry, food industry, wood economy, beauty industry, pharmaceutical industry, renewable energy and supply chains associated with the markets of these products and services.

The bio-based economy supports the creation of an innovative, resourse-efficent and competitive economy that "reconciles food security with the use of renewable resources for industrial purposes, while ensuring environmental protection" and branches related to it are becoming ones of the biggest employers (Hadynski, 2015).

\section{THE ESSENCE OF THE CONCEPT OF THE BIOECONOMY IN TERMS OF THE TRIPLE TRIAD}

According to various definitions of the bioeconomy in the literature (McCornik, 2013; Schmind et al, 2012 ; Horizon 2020, The EU Framework... ), emphasis should be primarily put on the following issues:

Copyright (C) 2017 The Authors. Published by Aleksandras Stulginskis University. This is an open-access article distributed under the terms of the Creative Commons Attribution License (CC-BY 4.0), which permits unrestricted use, distribution, and reproduction in any medium, provided the original author and source are credited. 
1. transformation - the bioeconomy is the process of transformation of the traditional economy, the in statunascendi field, having its internal dynamics;

2. economic nature - within the meaning of neoclassical economics, it offers specific goods and services, it applies a microeconomic account and meets the demands;

3. endogenous changes of the technological economy - it could be seen as a response to the challenges of the sustainable development strategies or as a reformulating of the objectives of the European Union after the defeat of the Lisbon Strategy (The Lisbon Special..., 2000) aimed at building a competitive advantage of the Union.

Analysing the aforementioned processes in the economy that show the transition towards the bioeconomy, it can be perceived as a specific challenge faced by conventional economics:

I. Operator triad - it operates on the basis of the market institutions in the classic and traditional sense. It is a process that occurs among businesses, consumers and the state where it is the companies that bear the risk of conducting such an economic activity and shoulder the burden of the market challenges; the consumers are ready for a different model of consumption, aware of their market choices and able to accept a different / higher price; and the State which bears the burden of expenditure on R \&; D (Research and Development) and is responsible for education, it conducts specific development policies and creates the right climate for entrepreneurship development;

II. Key features triad - it can provide an opportunity to balance production and its low emissivity and also it can switch the economy to alternative sources of energy. Innovation, locality and networking of the links pertain to the range of solutions within Circular Economy (Circular Economy, 2015);

III. Challenges triad - it means following the path of the bioeconomy. If it is treated as a complex challenge for the whole economy, in practice it will determine the number of problems which the economy should deal with, i.e.:

- reindustrialisation understood as the conversion of the economy of the European Union to the economy functioning mainly in the closed model and a qualitative change in the industry, concerning not only industries directly related to the use of natural resources;

- international competitiveness, which can be understood as the use of the gap / technological advantage in the field of the bioeconomy;

- the issue of sustainability as an inherent feature of the whole economy.

Source: Authors' own conception

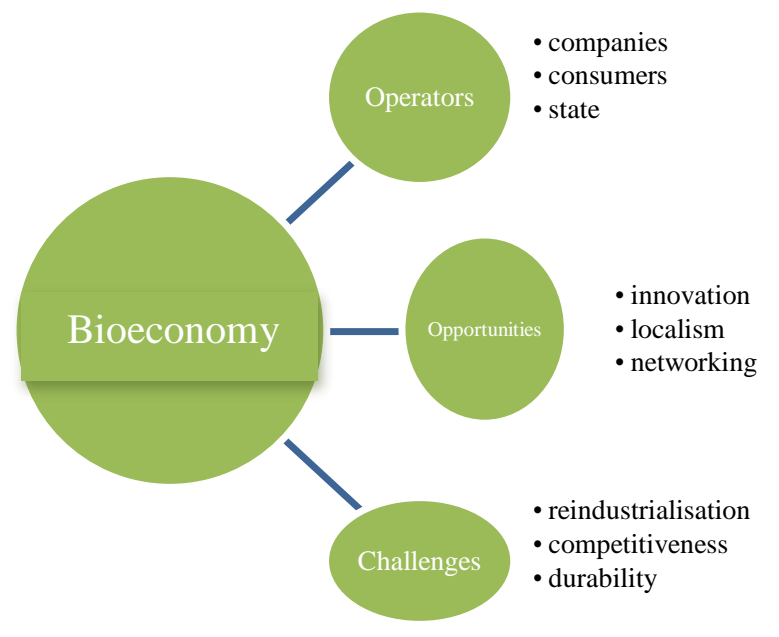

Figure 1. Bioeconomy triad of challenges

Apart from the distinct economic trait - the development of the certain production sectors, offering specific goods and services, the bioeconomy has a well-marked environmental feature - both in terms of the use of natural resources and in the sense of activities aimed at the regional use of these resources. The development of agriculture, forestry, fisheries and aquaculture is associated with the resources which are essential for the production of biomass, such as acreage of land and water, soil fertility, water, ecosystems and minerals, which require a sustainable management in these sectors.

It is also important to remember that the economy of the European Union is vulnerable to a decreasing supply and changes in the markets of fossil resources, mainly due to the reliance on those resources (Innovating for Sustainable growth..., 2012). This is another reason why the EU economy should become a low-carbon and resource-efficient economy based on bioproducts and bioenergy. It should pursue the so-called green growth. It seems that the evolution of the bioeconomy, seen as a concept of a development, is moving precisely in the direction of "greening" - it is not to be merely a modern and extremely efficient method of production of food, medicines or other products; emphasis should be shifted to social participation or balancing the production.

\section{Bioeconomy in regional terms - case study: Malopolska voivodship}

The bioeconomy is a category which has a great importance for the formation of the specialisation and regional development. The European Union has initiated the identification and selection of specific areas of smart specialisation by its regions. In Poland, there has been done the choice of five generic smart specialisations: a healthy society, the agro- 
food bioeconomy, forestry, wood and environmental economy, sustainable energy, natural resources, waste management, innovative technologies and industrial processes. Some regions in Poland have chosen the bioeconomy as one of the main leading smart specialisations of the region, others have introduced selected elements from a wide range of the components of the bioeconomy to the adopted regional specialisations (Adamowicz, 2017).

Bioeconomy is, on the one hand, the process of profound changes of the face of the conventional economy, and on the other hand, the result of this process. It has the perspective of both the EU - through the strategy and policy of supporting the development and also a regional perspective - through the selection within the strategy of the development of the smart specialisation - alongside the media, ICT, chemistry for Małopolska province in the course of the bioeconomy. That is exactly life science specialisation, the bioeconomy (in the strict sense) and energetics - balanced energy.

\begin{tabular}{|c|cc|}
\hline Share of Poland's GDP (\%) & 7,7 & 5 \\
\hline Unemployment rate (\%) & 6,7 & 4 \\
\hline Persons employed in industry (\%) & 31,1 & 12 \\
\hline Persons employed in agriculture (\%) & 11,6 & 3 \\
\hline Persons employed in services (\%) & 57,3 & 7 \\
\hline Spending of GDP on R\&D (\%) & 1,38 & 2 \\
\hline Share of business in financing R\&D & 29 & 8 \\
\hline Employment in R\&D & 1,03 & 2 \\
\hline
\end{tabular}

Source: Authors' own calculation on the base of GUS figures

Figure 2. The economic potential of Małopolska province in Polish context (\% / place in Poland compared to 16 provinces)

In terms of economic development Małopolska province is quite a specific region of Poland due to the peculiar dichotomy - on the one hand, in the region there is high expenditure on R\&D and self-employment in this sector. On the other hand, the region is struggling with relatively high unemployment (which puts it on the 4th place out of all provinces) and a high percentage of people employed in agriculture (3rd place in the country).

It is extremely difficult to measure the bioeconomy potential of Małopolska province. It is relatively easy to identify its economic aspect (diagram above), whereas defining the environmental aspect may pose some difficulties. This is due to the fact that there is still lack of clear indicators of the environmental determinants of economic development towards the bioeconomy. In Poland, there has not yet been created this type of indicators that would quantify the components of the natural environment preserved in an appropriate culture, and at the same time, ready to be economically exploited.

It seems that the clusters operating on the basis of selected smart specialisation (e.g. Life Science Cluster bringing together administration, business environment institutions, the scientific community and 35 business entities or BBI Bio-Based Industries Joint Undertaking) constitute the most visible initiatives in the region. They are flagship projects "in the spirit of" bioeconomy in the Małopolska province. However, they are temporarily treated as pilot schemes and are not structurally related to regional development strategies.

In the case of Malopolska province it is extremely important to see the transformation of the economy in the direction of bio in the light of:

- diversification of activities in rural areas;

- possibility of increasing the income of companies undertaking such activities on account of the higher added value of the bioeconomy production;

- development of functioning value chains and construction of the new ones, which can be a tool for the revitalisation of rural areas;

- $\quad$ significant impact on the development of the labour market - especially in rural and less developed areas (Chyłek, 2012);

- $\quad$ in the context of the union (the European Union) it is of vital importance not to overlook a kind of commitment to substitute at least $30 \%$ of chemical materials for organic and biodegradable materials, as well as the commitment of Europe to achieve a $25 \%$ threshold of the use of biofuels in the structure of energy production for transport.

If the balanced management of natural resources, sustainable production methods, improvement of public health, climate change mitigation, integration and inclusiveness of social development are considered to be the greatest challenges facing modern economy on both international and national scale, the bioeconomy should be seen as an answer to the outlined problems.

The bioeconomy is a category which has a great importance for the formation of the specialisation and regional development. The European Union has initiated the identification and selection of specific areas of smart specialisation by its regions. In Poland, there has been done the choice of five generic smart specialisations: a healthy society, the agro- 
food bioeconomy, forestry, wood and environmental economy, sustainable energy, natural resources, waste management, innovative technologies and industrial processes. Some regions in Poland have chosen the bioeconomy as one of the main leading smart specialisations of the region, others have introduced selected elements from a wide range of the components of the bioeconomy to the adopted regional specialisations.

It can be indicated that in Małopolska province there is a dual model of development, which may have a significant impact on the pace of the development and the future of the bioeconomy in the whole region. On the one hand, there are dynamically developing sectors of modern technology concentrated in the voivodship city (Cracow) and in the district cities (Oświęcim, Wadowice, Tarnów, Bochnia, Nowy Sacz). On the other hand, there is the development of rural areas with their potential that is crucial for the bioeconomy, where there is the fragmentation of farms, their inconsiderable average size, unregulated ownership relations and the problem of set-aside land.

Another type of barriers emerges here - institutional barriers - related to the access to knowledge, resistance to changes and to everything that is new. As indicated in the literature (Żmija, Czekaj, 2014), Malopolska province has development opportunities in many fields connected with the development of the bioeconomy. Agricultural producers from the area of the voivodship are able to ensure food security. Moreover, natural resources are a source of raw materials for energy industry, chemical industry and biotechnology one. It is also important to bear in mind the special significance of Malopolska province for the protection of the natural environment and preservation of the traditional rural landscape.

From the point of view of the use of the bioeconomy potential of Małopolska province, a few elements that may constitute challenges in the future (both in the short- and long-term perspective) should be pointed out. This issue may be viewed in terms of:

- institutional conditionings which are associated with the legal order, fiscal policy, expenditure on $\mathrm{R} \& \mathrm{D}$, the condition of infrastructure and availability of different sources of financing. They can be both a stimulant and a deterrent of the development;

- conditionings related to the transfer of knowledge, where the key role is played by the quality of cooperation among science and practice, consulting, dissemination of information and the use of modern forms of communication (The Knowledge Based Bio-Economy (KBBE) in Europe...);

- social conditionings - the main problem here is the quality of human capital, willingness of the local community to take new initiatives, the quality of the labour force and the access to qualified personnel;

- environmental conditionings in terms of the access to sustainable natural resources as a prerequisite for the production in certain sectors in a sustainable development perspective.

Small research companies, in the context of new business models, could become a special chance for the development of Małopolska province in the aspect of biotechnology. Those firms, which can be more flexible in relation to the changing environment, offer their know-how to bigger companies with an implementation and production profile (The Bioeconomy to 2030, 2016). That is the solution suggested in the latest OECD strategic document regarding the bioeconomy.

\section{Opportunities and difficulties in the development of bioeconomy}

However, it is important to be aware that, the bioeconomy cannot yet be called a new wave of the economic development; nevertheless, it offers great opportunities for innovation and growth, which may be understood as a starting point for the process of reindustrialisation of Europe, perceived as a new path of the development. For years' analysis and the OECD forecasts have been indicating that the development of the biotechnology and the bioeconomy will help meet the challenges facing the world. Indeed, bioeconomy may be a key factor in maintaining the economic growth and job creation. What is more, it can be assumed that a further innovative development in the bioeconomy will reduce the dependence of production and industry from the decreasing resources of conventional fuels.

The increase of the competitiveness of the regional economy should be primarily based on its own potential. Meeting this objective will enable specialisation in the areas where it is possible to achieve economic success on a European scale. The bioeconomy is the sector, which in case of Malopolska region, has a very large potential of impact on an economic and social development. Its development implemented on the basis of innovative technologies, processes and products can contribute to the increase of the effectiveness and efficiency of the production of high quality safe food. It can also generate an increase in sales and profitability, not only in the food and agriculture industry, but in other industries as well.

The underlying message is that the bioeconomy is set to face considerable challenges in the years ahead. The importance of the bio-based sectors is expected to dwindle somewhat, both as a motor of jobs and growth. The factors underlying this result are mainly "structural" (Drivers from...).

Creating competitive advantages of the region in the sector of the bioeconomy should take place within the value chains. This necessity stems from the need to strengthen the links of cooperation in traditional sectors of the economy. It also results from the intention to create appropriate conditions for the opening of these sectors for innovation and cooperation with the scientific community.

\section{SUMMARY}

If the balanced management of natural resources, sustainable production methods, improvement of public health, climate change mitigation, integration and inclusiveness of social development are considered to be the greatest challenges facing modern economy on both international and national scale, the bioeconomy should be seen as an answer to the outlined problems. 
It is also essential to draw attention to the fact that the kind of innovation introduced within the bioeconomy solutions should not only originate in the scientific and research centres, but it should also be the result of stakeholders' participation (e.g. producers, farmers, etc.) and their practical knowledge and experience.

The development of the bioeconomy must be recognized as a whole through the concept of sustainable development. This means that a new type of economy should not only solve the problems related to environmental protection (in global and local terms) but it should also supply bio-based products (food, industrial products, fuel) within the effective value chains.

The bioeconomy gives Małopolska province a chance to build its own brand provided that there is a proper coordination of policies - innovation policy and the one regarding the development of agriculture and rural areas. It should be stressed out that the plan of the development of the local economy in Małopolska province should be based on such an understanding of the bioeconomy in which we have to deal with the sustainable use of renewable biological resources, based on biotechnological innovations in production processes so as to meet both private and public needs.

It is also the case of securing an adequate supply of public goods, primarily related to the appropriate quality of the natural environment, through shorter food supply chains, more efficient energy production, soil protection and maximizing the benefits of the exploitation of alternative uses of agricultural land and forest.

\section{REFERENCES}

1. McCornik, K., Kautto, N. 2013. the Bioeconomy in Europe: An Overview. Sustainability, Vol. 5, pp. $2589-2608$. www.mdpi.com/journal/sustainability (accessed on 04/10/2017);

2. Drivers of the European Bioeconomy in Transition (Bioeconomy2030) - an exploratory, model-based assessment, EC, Joint Research Centre, IPTS, Seville.

3. The Lisbon Special European Council. 2000. Towards a Europe of Innovation and Knowledge, http://eur-lex.europa.eu/legalcontent/PL/TXT/?uri=uriserv:c10241 (Accessed on 23/08/2017);

4. Horizon 2020, The EU Framework Programme for Research and Innovation, http://ec.europa.eu/research/bioeconomy/index_en.htm; (accessed on 02/03/2018;

5. Hadynski, J. 2015. The bio-based economy in the European Union's development strategies. Economic and Regional Studies, Vol. 8, No. 1.

6. Innovating for Sustainable Growth: A Bioeconomy for Europe, 2012, Communication from the Commission to the European Parliament the Council, The European Economic and Social Committee and the Committee of the Regions, European Commission, Brussels

7. Adamowicz, M. 2017. Bioeconomy - concept, application and perspectives, Zagadnienia Ekonomiki Rolnej, Vol.1 (350), pp. 2949. http://www.zer.waw.pl/fulltxt.php?ICID=1232987;

8. Chyłek, E.K. 2012, Bioeconomy in the agricultural and food sector, Food Industries, 2012/66.

9. Circular Economy Strategy, 2015, European Commission, http://ec.europa.eu/environment/circular-economy/index.en.htm;

10. Żmija, J., Czekaj, M. 2014. The Diversity of form production as the basis for the development of bio-economy in Malopolska provience, Economic and Regional Studies, Vol 7, No. 4, pp. 33-42.

11. The Bioeconomy to 2030: designing a policy agenda. 2016. OECD, International Futures Programme;

12. The Knowledge Based Bio-Economy (KBBE) in Europe: Achievements and Challengers. 2010. http://www.bioeconomy.net/reprts/files/KBBE_2020_BE_presidency.pdf (Accessed on 01/03/2018).

13. Schmind, O., Padel, S., Levidow, L. 2012. The Bioeconomy Concept and Knowledge Base in a Public Goods and Farmer Perspective. Bio-based and Applied Economics, Vol. 1(1), pp. 47-63. 